\begin{abstract}
La Revista Colombiana de Obstetricia y Ginecología rinde un homenaje al profesor Dr. Roberto Caldeyro-Barcia, con motivo de su reciente fallecimiento y con este fin publica los testimonios que en su memoria presentan algunos de sus alumnos colombianos
\end{abstract}

\title{
El Maestro ha muerto, viva su memoria
}

\section{Dr. Edgard Cobo C.*}

En el aciago día del 2 de noviembre pasado, falleció en Montevideo, su bella ciudad natal, el Profesor Roberto Caldeyro-Barcia, padre indiscutible de la Medicina Perinatal.

El privilegio de ser su primer alumno colombiano y la orgullosa satisfacción de haber abierto el camino a numerosos compatriotas que fueron a disfrutar sus conocimientos, sembró mi vida profesional y personal de gratísimos recuerdos y muy profundas enseñanzas.

Cuando promediaba mi tercer año de residencia en Ginecología y Obstetricia, en Cali y me sentía tentado a aceptar una beca para entrenarme en oncología en el Hospital Memorial de Nueva York, el Profesor Jorge Escobar Soto me enseñó los trabajos de Alvarez y Caldeyro, a quienes algunos colegas de ese entonces creían una sola persona con apellido nobiliario. La lectura de esos artículos me impresionó a tal punto, que en una de las decisiones

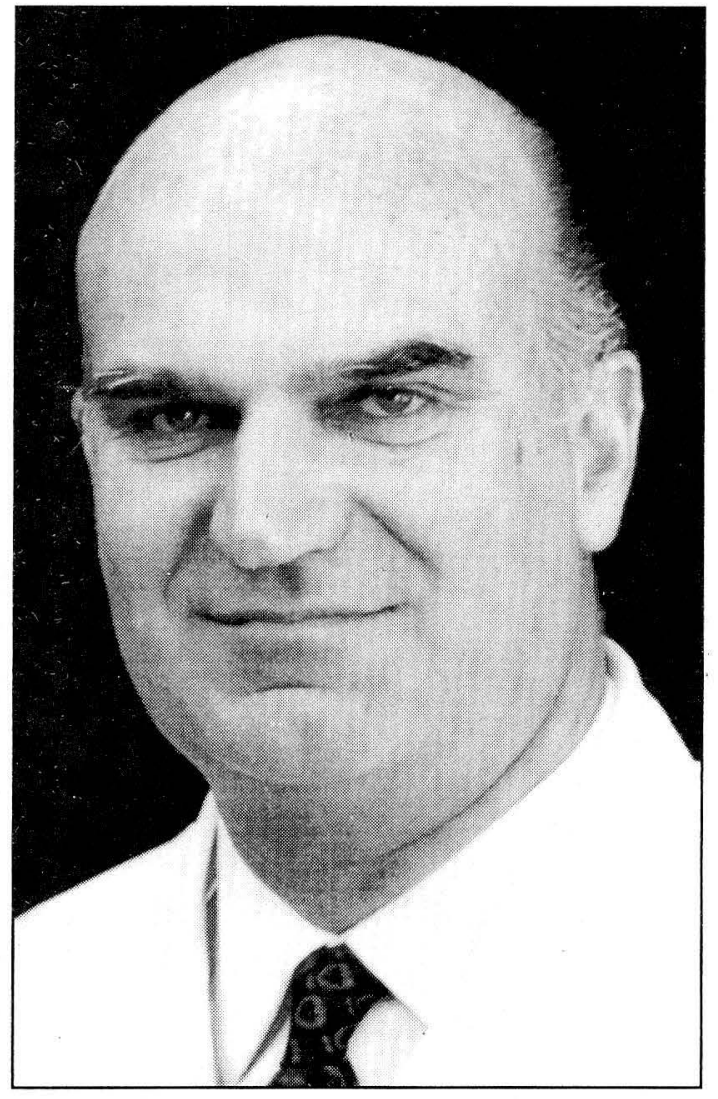
más acertadas de mi vida, cambié la oncología por la fisiología clínica. Me resultaba excitante leer trabajos científicos que midieran los resultados y se fundamentaran en el método científico, una versión de la literatura médica casi inédita en una especialidad tan anecdótica y artesanal, como era entonces la nuestra. Pero además, estos artículos tenían un cierto encanto indefinible que sólo vine a comprender 6 meses después cuando llegué a Montevideo como becario del entonces Servicio de Fisiología Obstétrica, y sentí desde el primer momento la fuerza de la personalidad de Roberto Caldeyro y la exquisita sensibilidad de Hermógenes Alvarez.

Roberto Caldeyro, quien fuera convirtiéndose después en Boby para sus amigos, desarrolló una imponente carrera científica, ya repetidamente relatada y conocida y que yo solo voy a resumir al vuelo, diciendo que publicó con sus numerosos colaboradores y discípulos más de 500 trabajos de investigación básica y clínica, numerosos

Profesor Emérito de Obstetricia y Ginecología

Universidad del Valle capítulos en libros monográficos y de texto y que fue invitado a casi todos los eventos científicos importantes relacionados con la Perinatología celebrados en el mundo, casi hasta la misma víspera de su fallecimiento. "Siempre esperado, siempre distinguido, siempre querido, siempre recordado". Pocos meses antes de su muerte se encontraba entusiasmado editando el libro de texto: Obstetricia y Perinatología, en cuya autoría me incluyó. "Tengo el honor de invitarte a participar", decía su carta, en un derroche de elegancia que le era muy propio y capaz de invertir los términos siendo, como en efecto es, que el honrado en esta circunstancia era obvio.

Siento la profunda necesidad de rendir homenaje a su memoria, recordando algunas otras características de su multifacética personalidad, que fueron, como casi todas las suyas, únicas.

Fue poseedor de una extraordinaria capacidad para comunicarse con los demás. Tenía el don de la palabra fácil y exacta que se complementaba con su figura apuesta y elegante..Era el Gran Comunicador. Captaba con rapidez envidiable el sentir de quiénes tenía al frente y comenzaba a hilvanar un discurso lógico, ordenado y siempre seductor. "Su entusiasmo es contagioso, sus conferencias eximias", escribió refiriéndose a él, el Premio Nobel Bernardo Houssay al presentarlo en 1963, como ganador del Premio Braun Menéndez. Así logró derretir, que esa es la palabra, a los grandes auditorios del mundo incluidos aquellos que inconscientemente se resistían a aceptar que la ciencia hablara castellano y menos aún que lo hiciera desde un pequeño y austero país latinoamericano. Así fue como llegó a sentarse en las grandes mesas y asistir a los grandes convites del mundo científico.

Otra faceta impresionante fue su extraordinaria capacidad física, que lo llevaba a trabajar hasta 20 horas diarias, sin menguar su rendimiento al día siguiente. Se ocupaba de detalles mínimos, aún en los momentos de máxima exigencia, cuando mantenía una abundante correspondencia con casi todos los Centros de investigación y de enseñanza que interesaban a los trabajos en 
curso en su laboratorio. Guardo el recuerdo de una carta de dos auxiliares de enfermería de un país centroamericano, preguntando su opinión sobre la inducción del parto, cuya respuesta me enseñó, regalándoles una didáctica expresión de sus conocimientos, que imagino fue dictada en las horas más avanzadas de la noche.

No menos excepcional fue su capacidad administrativa. Pienso que Caldeyro fue el primer gerente de la empresa científica en la América Latina. Sin duda alguna, sus características de visionario lo llevaron a este descomunal empeño. Era notable su capacidad para adquirir fondos destinados originalmente a otros temas científicos considerados prioritarios, para invertirlos en el estudio de la eyección láctea, la fisiología del parto o la fisiopatología del útero, en una época donde la anticoncepción comenzaba a acaparar los fondos disponibles y aún los no disponibles. Resultaba casi fantástico ver cómo las grandes agencias financieras, y las pequeñas, muy pequeñas, agencias nacionales iban cediendo bajo el sortilegio de su palabra convincente y de la fuerza con que presentaba su evidencia científica.
Estos dones con los que fue bendecido por los dioses, hicieron de Montevideo un Centro universal de referencia científica, una Meca a donde fuimos a orarle al método científico jóvenes y viejos de todas las latitudes y de todas las çreencias. En el Servicio de Fisiología Obstétrica, durante mi época de becario, se oían, se hablaban y se malhablaban casi todos los idiomas del mundo. Decía Jalil Gibran: "Si en los ojos de los jóvenes hay fuego, en los ojos de los viejos hay luz". Recordándolo quiero pensar que la Medicina Perinatal no ha llegado a valorar en toda su magnitud, la contribución pionera que hicieron Don Hermógenes Alvarez (la luz), al inducir en su alumno de Obstetricia Roberto Caldeyro (el fuego), las ideas que él logró desarrollar gracias a su poderosa inteligencia y llegar a niveles que tal vez su profesor nunca imaginó.

Paz en sus tumbas y que brillen para ellos el fuego y la luz eternas.

Cali, diciembre de 1996

\section{En memoria de mi maestro. El profesor Dr. Roberto Caldeyro Barcia}

El pasado 2 de noviembre de 1996 falleció en su Ciudad natal Montevideo a la edad de 75 años, el Profesor Dr. Roberto Caldeyro-Barcia.

Caldeyro fue el científico que en América Latina y quizá en el concierto mundial más aportes hizo al conocimiento de la fisiología uterina durante el embarazo y el parto.

Trabajando con quien fuera su Profesor, el notable Obstetra Uruguayo Dr. Hermógenes Alvarez, describieron entre 1948 y 1950 todas las condiciones cualitativas que debe tener la contractilidad uterina normal durante el trabajo de parto. Por esa misma época realizaron por primera vez en una embarazada con feto vivo y sano el procedimiento conocido como Amniocentesis, el cual con el devenir de conocimientos metabólicos, cromosómicos, etc., ha permitido realizar diagnósticos de diferentes condiciones fetales, aún desde épocas muy tempranas de la gestación.

En la década del 50 al 60 describió el "Triple Gradiente Descendente" de igual manera introdujo otros conceptos que han sido pioneros en la atención obstétrica como son la descripción (por métodos internos) de las contracciones uterinas durante el embarazo, el preparto, el parto y el puerperio: la influencia de la posición materna sobre las contracciones uterinas y los parámetros clásicos de intensidad, frecuencia y actividad uterina ("Unidades Montevideo") durante el trabajo de parto.

Iniciando la década del 60 publicó trabajos originales con investigaciones en cardiotocografía fetal. Como consecuencia de esas investigaciones se pudo difundir la expresión electrónica de los efectos compresivos sobre el cerebro fetal de las contracciones uterinas con las membranas ovulares rotas (dips tipo I). También trabajos clásicos sobre asfixia y acidosis del feto por insuficiencia en los intercambios placentarios cauusados por las contracciones uterinas (dips tipo II y III), finalizando esta época en el concepto de la útero-inhibición para un manejo adecuado del Sufrimiento Fetal Agudo Intraparto.

Comenzando la década del 70, quien esto escribe, tuvo la fortuna de permanecer durante dos años en el Centro Latinoamericano de Perinatología Humano (CLAP) en Montevideo, Uruguay, recibiendo sus conocimientos y aprendiendo de su personalidad. Como lo manifiesto en el prólogo del libro Obstetricia de Alto Riesgo, "Caldeyro ha sido el modelo profesional que me ha guiado en todo mi tránsito a través de la Docencia y la Investigación".

Fue en la década del 70 en la cual pude observar de cerca su extraordinaria capacidad Docente e Investigativa. En su centro de Perinatología (concepto éste que él introdujo para nominar ésta multidisciplinaria sub-especialidad), las generaciones de Obstetras y- Neonatólogơs que pasamos en las décadas del 70 y el 80 tuvimos el privilegio de ser modulados directamente por la influencia de sus enseñanzas.

Caldeyro, el Maestro siempre fue un genio y siempre conservó el don de gente y el afecto especial por todos sus discípulos.

Desde Colombia donde estamos muchos de sus discípulos (Edgar Cobo Cobo, Antonio Soto Yances, Jaime Barrios Amaya, Hernán Arroyave, Edgar Iván Ortiz Lizcano, entre otros muchos) le rendimos un homenaje al Maestro cuya trayectoria científica será el mejor legado que le podemos entregar a todas las nuevas generaciones.

RODRIGO CIFUENTES B., MD., PH.D. Profesor Titular - Jefe Departamento Ginecología y Obstetricia Escuela de Medicina Universidad del Valle Cali - Colombia. 